\title{
A survey of Babesia spp. and Hepatozoon spp. in wild canids in Israel
}

\author{
Maayan Margalit Levi ${ }^{1}$, Yaarit Nachum-Biala ${ }^{1}$, Roni King ${ }^{2}$ and Gad Baneth ${ }^{1^{*}}$ (D)
}

\begin{abstract}
Background: Babesia spp. and Hepatozoon spp. are apicomplexan parasites that infect a variety of animals, including canids. Their life-cycle includes an invertebrate hematophagous vector as a definitive host and vertebrates as intermediate hosts. The aims of this study were to investigate the prevalence and risk factors for Babesia spp. and Hepatozoon spp. infections in wild golden jackals (Canis aureus) and red foxes (Vulpes vulpes) in Israel and to compare spleen with blood sample polymerase chain reaction (PCR) for the detection of infection.

Results: Blood and spleen samples from 109 golden jackals and 21 red foxes were tested by PCR for the detection of Babesia spp. and Hepatozoon spp. using primers for the 185 ribosomal (r) RNA gene. Hepatozoon canis was detected in 50/109 (46\%) of the jackals and 9/21 (43\%) of the foxes. "Babesia vulpes" (the Babesia microti-like piroplasm) was detected in 4/21 (19\%) of the foxes and in none of the jackals. A previously unknown genotype termed Babesia sp. MML related to Babesia lengau (96-97\% identity) was detected in 1/109 (1\%) of the jackals and 4/21 (19\%) of the foxes. Further characterization of this genotype carried out by PCR of the rRNA internal transcribed spacer 2 (ITS2) indicated that it had only $87 \%$ identity with the $B$. lengau ITS2. Sex (male or female), age (juvenile or adult) and geographic zone (North, Central or South Israel) were not found to be significant risk factors for these protozoan infections. The prevalence of "B. vulpes" and Babesia sp. MML infections was significantly higher in foxes compared to jackals $\left(X^{2}=15\right.$. $65, d f=1, P<0.005)$, while there was no statistically significant difference in the rate of $\mathrm{H}$. canis infection between these two canid species. A fair agreement beyond chance between identification in the blood and spleen of $\mathrm{H}$. canis was found in 21 animals from which both blood and spleen samples were available $(k=0.33)$.

Conclusions: This study describes a high prevalence of $H$. canis infection in foxes and jackals and is the first report of "B. vulpes" infection in Israel, an area where Ixodes spp. are rare. It describes infection with a previously unknown genotype of Babesia related to $B$. lengau from Africa.
\end{abstract}

Keywords: Golden jackal, Canis aureus, Red fox, Vulpes vulpes, Hepatozoon canis, "Babesia vulpes", Babesia lengau

\section{Background}

Blood parasites of the genera Babesia and Hepatozoon are apicomplexan protozoans which infect a large variety of animals, including canids [1-4]. Their life-cycles comprise an invertebrate hematophagous vector as a definitive host and vertebrates including domestic dogs and wild canids as intermediate hosts. Babesia spp. are transmitted by the saliva of ixodid ticks, infect erythrocytes and cause babesiosis, which is characterized clinically mainly by hemolysis and anemia. Infection with Babesia spp. can be sub-clinical, moderate or severe and cause potentially fatal disease $[3,5]$.

\footnotetext{
* Correspondence: gad.baneth@mail.huji.ac.il

'Koret School of Veterinary Medicine, The Hebrew University of Jerusalem,

Rehovot, Israel

Full list of author information is available at the end of the article
}

Hepatozoon spp. have a diverse range of vertebrate and invertebrate hosts with specific hematophagous invertebrate vectors that infect vertebrate hosts by ingestion of the invertebrate host containing mature Hepatozoon spp. oocysts. Some Hepatozoon spp., infect leukocytes of mammals, whereas other species adapted to lower vertebrates mainly infect the erythrocytes of their vertebrate hosts. Hepatozoon spp. can cause sub-clinical infections, or induce a mild disease, and some species such as Hepatozoon americanum may cause severe and fatal disease in their hosts $[1,2,6]$.

Domestic dogs and wild canid species are often infected by the same species of Babesia and Hepatozoon, and from the evolutionary standpoint it has been suggested that these protozoan pathogens have been transferred to the domestic dogs from their wild canid species relatives. It is, 
therefore, likely that domestic dogs and wild canids living in the same geographical regions may share the same Hepatozoon and Babesia spp. infections [2, 7]. However, different habitats of domestic and wild canids, the specific susceptibility of the canid host species to the pathogen, and exposure to a different spectrum of hematophagous ectoparasite vectors are among the factors that may influence the probability of pathogen infection in domestic dogs and wild canid populations. Although there are several studies on the prevalence of Hepatozoon and Babesia species in wild canids from different parts of the world [8-13], in Israel there is little information on infection with these parasites in wild canids [14]. Hence, the aim of this study was to investigate the prevalence and risk factors for Babesia spp. and Hepatozoon spp. infections in the wild golden jackals (Canis aureus) and red foxes (Vulpes vulpes) in Israel.

As the spleen has a major role in removing bacterial and protozoal pathogens from the blood and often harbors protozoal infections in canids $[15,16]$, another aim of this study was to compare spleen with blood polymerase chain reaction (PCR) for the detection of Babesia and Hepatozoon infections. Knowing which tissue to choose for the best likelihood of parasite detection would be helpful for future studies.

\section{Methods}

\section{Jackals and foxes}

Spleen and blood samples were collected from golden jackals and red foxes by wardens of the Israel Nature and Parks Authority as a part of a national study on the prevalence of leishmaniosis in wildlife animals. Trapping of animals was performed by wardens of the Israel Nature and Park Authorities with an approved permit from this agency and the study was conducted adhering to the Hebrew University's guidelines for animal husbandry and use of animals in research. The data collected on the animals included the location of trapping in North, Central or South Israel, sex, and age (Table 1).

\section{DNA extraction, PCR and sequencing}

DNA was extracted from blood and spleen samples with a commercial purification kit (Illustra Blood GenomicPrep Mini Spin Kit; GE Healthcare, Buckinghamshire, UK), according to the manufacturer's instructions and a series of polymerase chain reaction (PCR) assays was run to identify Babesia spp. and Hepatozoon spp. infections. DNA from the blood of a laboratory-bred piroplasmid-free dog and from a dog naturally infected with Babesia vogeli and a dog naturally infected with Hepatozoon canis were used as negative and positive controls, respectively, and run with each reaction. PCR using the piroplasmid forward ( $5^{\prime}-\mathrm{CCA}$ GCA GCC GCG GTA ATT C-3') and piroplasmid reverse (5'-CTT TCG CAG TAG TTY GTC TTT AAC AAA
Table 1 Numbers of golden jackals and red foxes included in the study, sample types examined, region or origin, gender, age and infection values

\begin{tabular}{lll}
\hline & Golden jackal & Red fox \\
\hline Sample number and type & 65 & 17 \\
Blood & 63 & 9 \\
Spleen & 19 & 5 \\
Blood and spleen & 109 & 21 \\
Total & & \\
Region in Israel (\%) & $63(58)$ & $8(38)$ \\
North & $20(19)$ & $9(43)$ \\
Center & $21(19)$ & $2(10)$ \\
South & $5(4)$ & $2(9)$ \\
Unknown & & $9(43)$ \\
Gender (\%) & $52(48)$ & $8(38)$ \\
Male & $39(36)$ & $4(19)$ \\
Female & $18(16)$ & \\
Unknown & & $2(10)$ \\
Age (\%) & $14(13)$ & $3(14)$ \\
Juveniles & $24(22)$ & $16(76)$ \\
Adults & $71(65)$ & $9(43)$ \\
Unknown & & $0(19)$ \\
Infection rates (\%) & $50(46)$ & \\
Hepatozoon canis & Babesia vulpes" & $(19)$ \\
\hline
\end{tabular}

TCT-3') primers was performed to amplify an approximately 360 base pair (bp) partial sequence of the $18 S$ ribosomal (r) RNA gene of piroplasm and Babesia spp. [17, 18].

The PCR was run using $1 \mu \mathrm{l}$ primers $(10 \mu \mathrm{M}), 20 \mu \mathrm{l}$ Ultra-Pure Water (UPW) and $3 \mu \mathrm{l}$ DNA. The following conditions were used for amplification: $94{ }^{\circ} \mathrm{C}$ for $3 \mathrm{~min}$; 35 cycles of $94{ }^{\circ} \mathrm{C}$ for $30 \mathrm{~s}, 64{ }^{\circ} \mathrm{C}$ for $45 \mathrm{~s}$, and $72{ }^{\circ} \mathrm{C}$ for $30 \mathrm{~s}$; and $72{ }^{\circ} \mathrm{C}$ for $7 \mathrm{~min}$. The PCR was performed using the Syntezza PCR-Ready High Specificity kit (Syntezza Bioscience, Jerusalem, Israel).

A second PCR was performed on samples positive by the piroplasmid PCR for Babesia spp. to amplify a longer sequence of the Babesia $18 S$ rRNA gene. The primers used to amplify a longer $18 S$ rRNA DNA sequence were $522 \mathrm{~F}$ forward (5'-GTT GAT CCT GCC AGT AGT-3') and 1661R reverse (5'-AAC CTT GTT ACG ACT TCT C-3') which amplify $1700 \mathrm{bp}$ of the Babesia spp. $18 S$ rRNA gene [19]. The PCR was run using $1 \mu \mathrm{l}$ primers $(10 \mu \mathrm{M}), 20 \mu \mathrm{l}$ UPW and $3 \mu \mathrm{l}$ DNA. The following conditions were used for amplification with the $522 \mathrm{~F} / 1661 \mathrm{R}$ primers: $95{ }^{\circ} \mathrm{C}$ for $5 \mathrm{~min} ; 35$ cycles of $95^{\circ} \mathrm{C}$ for $60 \mathrm{~s}, 59^{\circ} \mathrm{C}$ for $60 \mathrm{~s}$, and $72{ }^{\circ} \mathrm{C}$ for $60 \mathrm{~s}$; and $72{ }^{\circ} \mathrm{C}$ for $5 \mathrm{~min}$. 
An additional PCR was performed to target the Babesia ribosomal operon internal transcribed spacer region 2 (ITS2) for some of the Babesia-positive samples which yielded a DNA sequence that did not match with a known species. This PCR was performed using primers FOR7 (5'-AGC CAA TTG CGA TAA GCA TT-3') and REV7 (5'-TCA CTC GCC GTT ACT AGG AGA-3') [20]. The following conditions were used for amplification: $95^{\circ} \mathrm{C}$ for $5 \mathrm{~min} ; 35$ cycles of $95^{\circ} \mathrm{C}$ for $60 \mathrm{~s}, 59^{\circ} \mathrm{C}$ for $60 \mathrm{~s}$, and $72^{\circ}$ $\mathrm{C}$ for $60 \mathrm{~s}$; and $72{ }^{\circ} \mathrm{C}$ for $5 \mathrm{~min}$.

PCR products were separated by electrophoresis in $1.5 \%$ agarose gel stained with ethidium bromide. Amplified samples were purified using EXOSAP (Exo-SAP, NEB; New England Biolabs, Inc. Ipswich, MA, USA), and sequenced from both sides at the Center for Genomic Technologies, Hebrew University of Jerusalem, Israel. The sequences were evaluated using the Chromas Lite software (Technelysium Pty Ltd., Brisbane, Australia) and compared to sequences deposited in GenBank using the Basic Local Alignment Search Tool (BLAST). A result was considered positive for a certain pathogen if it was the first match by BLAST and had at least a $97 \%$ identity with a known GenBank accession.

\section{Phylogenetic analysis}

Phylogenetic analysis was performed using the Molecular Evolutionary Genetics Analysis software MEGA, version 6 [21]. The Maximum Likelihoood method was used to infer tree topology. Confidence values for individual branches of the resulting tree were determined by a bootstrapping analysis in which a $70 \%$ or higher value was considered significant.

\section{Statistical analysis}

Data were analyzed using the Chi-square or Fisher's exact tests. Exact binomial 95\% confidence intervals (CI) were established for proportions. A $P$-value $<0.05$ was considered statistically significant. Comparison of spleen with blood sample PCR for the detection of Hepatozoon infections was calculated with the Cohen's kappa coefficient (k). Analyses were done using the SPSS ${ }^{\oplus} 21.0$ statistics software (IBM; Armonk, New York, USA).

\section{Results}

Spleen and/or blood samples were collected from 109 golden jackals (C. aureus) and 21 red foxes ( $V$. vulpes) (Table 1). The jackals originated from North $(n=63$, $58 \%)$, Central $(n=20,19 \%)$, and South Israel $(n=21$, $19 \%)$. No information was available on the location of five jackals. Fifty-two (48\%) of the jackals were males, 39 (36\%) were females, and gender was not recorded for 18. Some of the jackals were classified as juveniles $(n=14$, $13 \%)$ or adult $(n=24,22 \%)$ while there was no information on the age of 71 of the jackals.

The foxes originated from North $(n=8,38 \%)$, Central ( $n$ $=9,43 \%)$, and South Israel $(n=2,10 \%)$, and no information was available for two animals. Nine (43\%) of the foxes were males and $8(38 \%)$ were females while gender was not recorded for $4(19 \%)$ the foxes. The foxes were classified as juveniles $(n=2,10 \%)$ or adult $(n=3,14 \%)$. No information was available on the age of 16 of the foxes.

\section{Prevalence of infection}

Hepatozoon canis infection was identified in 50 out of 109 of the golden jackals (46\%; CI: 35-55\%) and in nine of 21 red foxes (43\%; CI: 20-60\%). "Babesia vulpes" (syns Babesia microti-like piroplasm, Babesia cf. microti, "Theileria annae") was identified in 4 of 21 red foxes (19\%; CI: 1$37 \%$ ) and in none of the jackals. Babesia sp. MML (after the initials of the student who is the first author of this manuscript), a previously unknown Babesia genotype related to Babesia lengau (96-97\% identity by $18 S$ rRNA gene sequence comparison) and $B$. lengau-like sequences (97\% identity) (Table 2) was identified in 1 of 109 golden jackals (1\%; CI: $0-3 \%$ ) and in 4 of 21 red foxes (19\%; CI: 1-37\%). However, further genetic characterization by PCR

Table 2 Babesia spp. DNA sequences from red foxes and a golden jackal from the current study used for the Babesia 18S rRNA gene phylogenetic analyses and their closest GenBank matches

\begin{tabular}{|c|c|c|c|c|c|c|}
\hline Sample number & Species & Host & GenBank ID & $\begin{array}{l}\text { Size of } 185 \text { rRNA } \\
\text { fragment (bp) }\end{array}$ & Closest GenBank entry/origin & Percent identity \\
\hline 910 & "Babesia vulpes" & Vulpes vulpes & KJ871348 & 302 & MF040155/ "Babesia vulpes"/ Turkey & 99 \\
\hline 917 & "Babesia vulpes" & Vulpes vulpes & KJ871349 & 307 & MF040155/ "Babesia vulpes"/ Turkey & 99 \\
\hline 1061 & "Babesia vulpes" & Vulpes vulpes & KJ871350 & 303 & MF040155/ "Babesia vulpes"/ Turkey & 99 \\
\hline 910 & "Babesia vulpes" & Vulpes vulpes & KJ871351 & 1638 & AY534602/Babesia sp. "Spanish dog"/ Spain & 99 \\
\hline 912 & Babesia sp. MML & Canis aureus & KJ956779 & 314 & KM025199/ Babesia sp./ South Africa & 98 \\
\hline 1017 & Babesia sp. MML & Vulpes vulpes & KJ956780 & 313 & KF270672/ Babesia lengau-like/ Zambia & 97 \\
\hline 913 & Babesia sp. MML & Vulpes vulpes & KJ956781 & 312 & KF270672/ Babesia lengau-like/ Zambia & 97 \\
\hline 913 & Babesia sp. MML & Vulpes vulpes & KJ956782 & 1604 & GQ411417/ Babesia lengau/ South Africa & 97 \\
\hline 1017 & Babesia sp. MML & Vulpes vulpes & KJ956783 & 1639 & GQ411417/ Babesia lengau/ South Africa & 97 \\
\hline
\end{tabular}


of the ITS2 indicated that it had only $87 \%$ identity with the B. lengau ITS2 (Table 3).

\section{Comparison of blood and spleen infection}

Altogether there were 65 blood and 63 spleen samples from jackals with 19 out of a total of 109 jackals from which both blood and spleen samples were taken. In addition, there were 17 blood and 9 spleen samples from foxes with 5 out of a total of 21 foxes which provided both blood and spleen samples. Hepatozoon canis was detected in $32 / 65(49 \%)$ of the jackal blood samples and in $23 / 63(37 \%)$ jackal spleen samples with a prevalence of $5 / 19(26 \%)$ in jackals from which both blood and spleen were available. It was detected in 5 of $19(26 \%)$ foxes with blood samples available and in 6 of 9 (67\%) foxes from which the spleen was available. "Babesia vulpes" was identified only in foxes and found in $4 / 17$ (26\%) of the fox blood samples and in none of the 5 fox spleen samples. Babesia sp. MML was detected in 1/65 (2\%) jackal blood samples and in no jackal spleens, while it was found in 3/17 (18\%) fox blood samples and 2/5 fox spleens (40\%). One of 5 foxes (20\%) which had both blood and spleen samples was positive in both organs. The level of agreement between detection in the blood and spleen was calculated for $H$. canis only due to the small sample size of the other pathogens and was based on using 21 animals who had both blood and spleen available and of which 15 were positive in at least one tissue. Cohen's kappa coefficient was 0.33 (CI: 0.06$0.60)$ with a fair level of agreement, between spleen and blood sample PCR for the detection of H. canis [22].

\section{Influence of host species, age, gender and geographical zone on infection}

The effect of host species (C. aureus vs $V$. vulpes) was statistically significant $\left(\chi^{2}=15.65, d f=1, P<0.005\right)$ for "B. vulpes" and for Babesia sp. MML which were more prevalent in red foxes, but not for $H$. canis $\left(\chi^{2}=0.065, d f=1, P\right.$ $=0.799$ ) found in similar prevalences in both jackals and red foxes. The effects of gender on the positivity for "B. vulpes" and Babesia sp. MML was statistically insignificant $\left(\chi^{2}=1.675, d f=1, P>0.05\right)$. The effect of age and gender on the positivity of $H$. canis were also statistically insignificant $\left(\chi^{2}=3.79, \chi^{2}=0\right.$, respectively, $\left.d f=1, P>0.05\right)$. There was not enough information to calculate the effect of age on positivity for "B. vulpes" and Babesia sp. MML. The effect of the geographical zone (North, Central and South Israel) on the positivity for "B. vulpes", Babesia sp. MML and for $H$. canis, was statistically insignificant $\left(\chi^{2}=2.04\right.$ for Babesia spp. and $\chi^{2}=4.224$ for $H$. canis; $\left.d f=2, P>0.05\right)$. However, for "B. vulpes" and for Babesia sp. MML, no positive animals were identified in the South of Israel, whereas in Central Israel one and two of 29 animals were positive for these Babesia spp., respectively, and in North Israel four and two of 71 animals were positive, respectively.

\section{Genetic and phylogenetic analysis}

The positive PCR products from all reactions were sequenced to provide an accurate identity by comparison to GenBank accessions. All $H$. canis sequences were identical to $H$. canis sequences deposited in GenBank (MF588668, MF588669) with identity levels of 99-100\%. Three $H$. canis sequences from golden jackals from this study were deposited in GenBank (KJ868814-KJ868816) and an additional three sequences from red foxes were also deposited (KJ868817-KJ868819) (Table 4). A phylogenetic analysis (Fig. 1) based on 325 bp partial sequences of the $18 S$ rRNA gene of Hepatozoon created using the Maximum Likelihood method based on the Hasegawa-Kishino-Yano model indicated that the six sequences deposited in GenBank clustered with a high bootstrap value with other $H$. canis sequences from domestic dogs, golden jackals and red foxes from Europe, Africa and Asia. The $H$. canis sequences clearly clustered separately from $H$. americanum, Hepatozoon felis and Hepatozoon ursi sequences.

"Babesia vulpes" sequences from this study were 99\% identical to "T. annae", Babesia sp. "Spanish dog" and "B. vulpes" sequences deposited in GenBank (KT580785, AY534602, MF040155, respectively). Four "B. vulpes" sequences from foxes in this study were deposited in GenBank (KJ871348-KJ871351) including a 1638 bp accession covering almost the whole $18 S$ rRNA gene (KJ871351). A phylogenentic tree constructed based on 279 bp partial sequences of the of the $18 \mathrm{~S}$ rRNA gene of Babesia using the the Maximum Likelihood method and the Kimura 2parameter model (Fig. 2) showed that "B. vulpes" sequences from this study clustered together with $B$. microti-like piroplasm, "B. vulpes" and "T. annae" sequences from foxes and dogs from Europe, Turkey and North America, and separately from other piroplasm species that infect a variety of animal host species. Another phylogenetic tree based on longer Babesia 18S rRNA gene sequences of 1453 bp

Table 3 DNA sequence analysis of the Babesia sp. MML genotype ITS2 fragments, their GenBank accession numbers and closest GenBank entry match

\begin{tabular}{|c|c|c|c|c|c|c|}
\hline Sample number & Species & Host & GenBank ID & Size of ITS-2 fragment (bp) & Closest GenBank entry/origin & Percent identity \\
\hline 1017 & Babesia sp. MML & Vulpes vulpes & KR709304 & 323 & KF510019/ Babesia lengau-like/ Zambia & 87 \\
\hline 912 & Babesia sp. MML & Canis aureus & MG461685 & 444 & KF510019/ Babesia lengau-like/ Zambia & 87 \\
\hline 1087 & Babesia sp. MML & Vulpes vulpes & MG461686 & 445 & KF510019/ Babesia lengau-like/ Zambia & 87 \\
\hline
\end{tabular}


Table 4 Hepatozoon canis DNA sequences from golden jackals and red foxes from the current study used for the Hepatozoon partial 185 rRNA gene phylogenetic analysis and their closest GenBank matches

\begin{tabular}{|c|c|c|c|c|c|c|}
\hline Sample number & Species & Host & GenBank ID & $\begin{array}{l}\text { Size of } 185 \text { rRNA } \\
\text { fragment (bp) }\end{array}$ & Closest GenBank entry/origin & Percent identity \\
\hline 2621 & Hepatozoon canis & Canis aureus & KJ868814 & 331 & MF588668/ Hepatozoon canis/ Mauritius & 99 \\
\hline 5622 & Hepatozoon canis & Canis aureus & KJ868815 & 337 & MF588668/ Hepatozoon canis/ Mauritius & 100 \\
\hline 997 & Hepatozoon canis & Canis aureus & KJ868816 & 326 & MF588668/ Hepatozoon canis/ Mauritius & 100 \\
\hline 1167 & Hepatozoon canis & Vulpes vulpes & KJ868817 & 325 & MF588669/ Hepatozoon canis/Mauritius & 100 \\
\hline 1316 & Hepatozoon canis & Vulpes vulpes & KJ868818 & 328 & MF588668/ Hepatozoon canis/ Mauritius & 100 \\
\hline 116 & Hepatozoon canis & Vulpes vulpes & KJ868819 & 330 & MF588669/ Hepatozoon canis/Mauritius & 99 \\
\hline
\end{tabular}

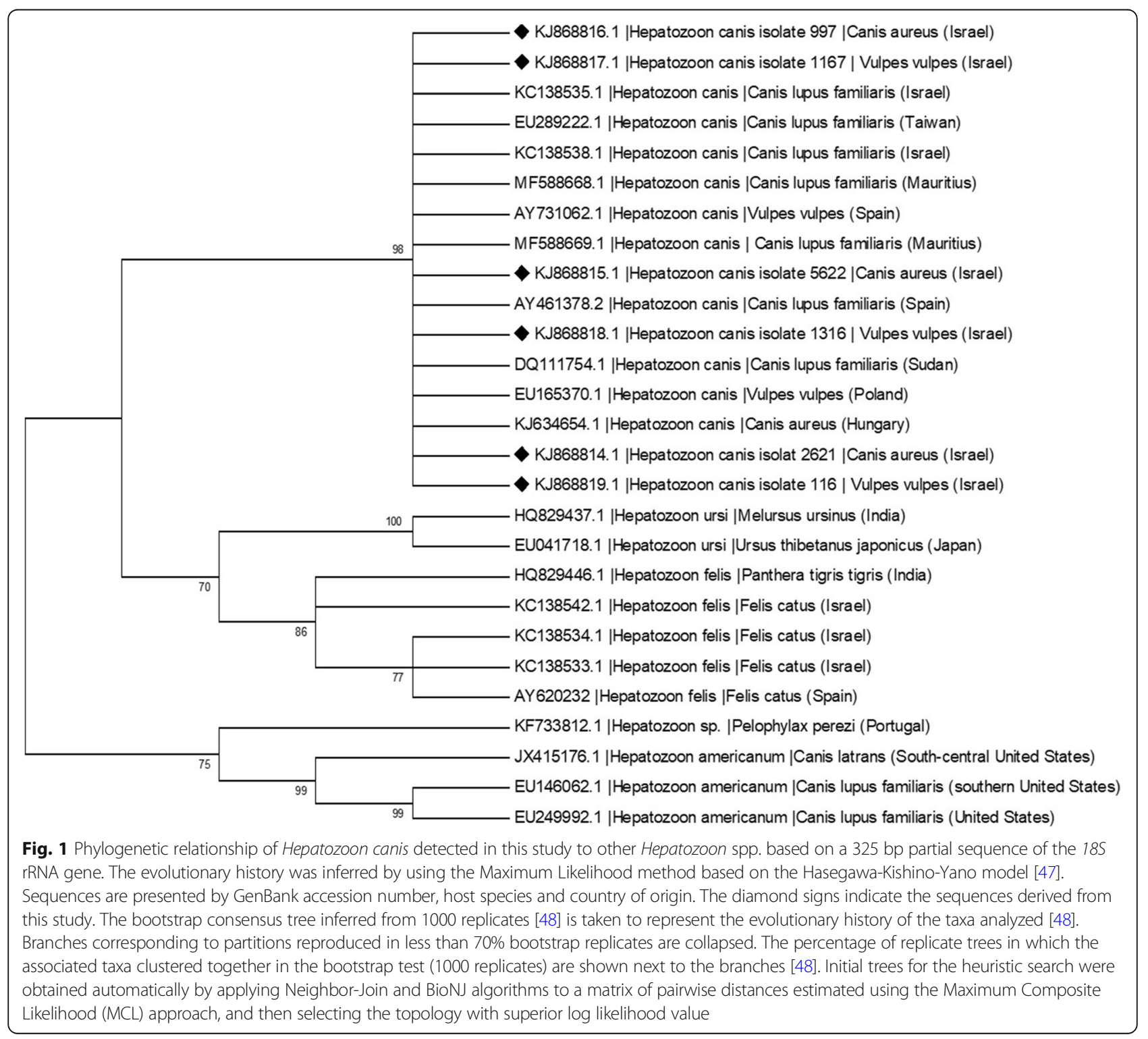




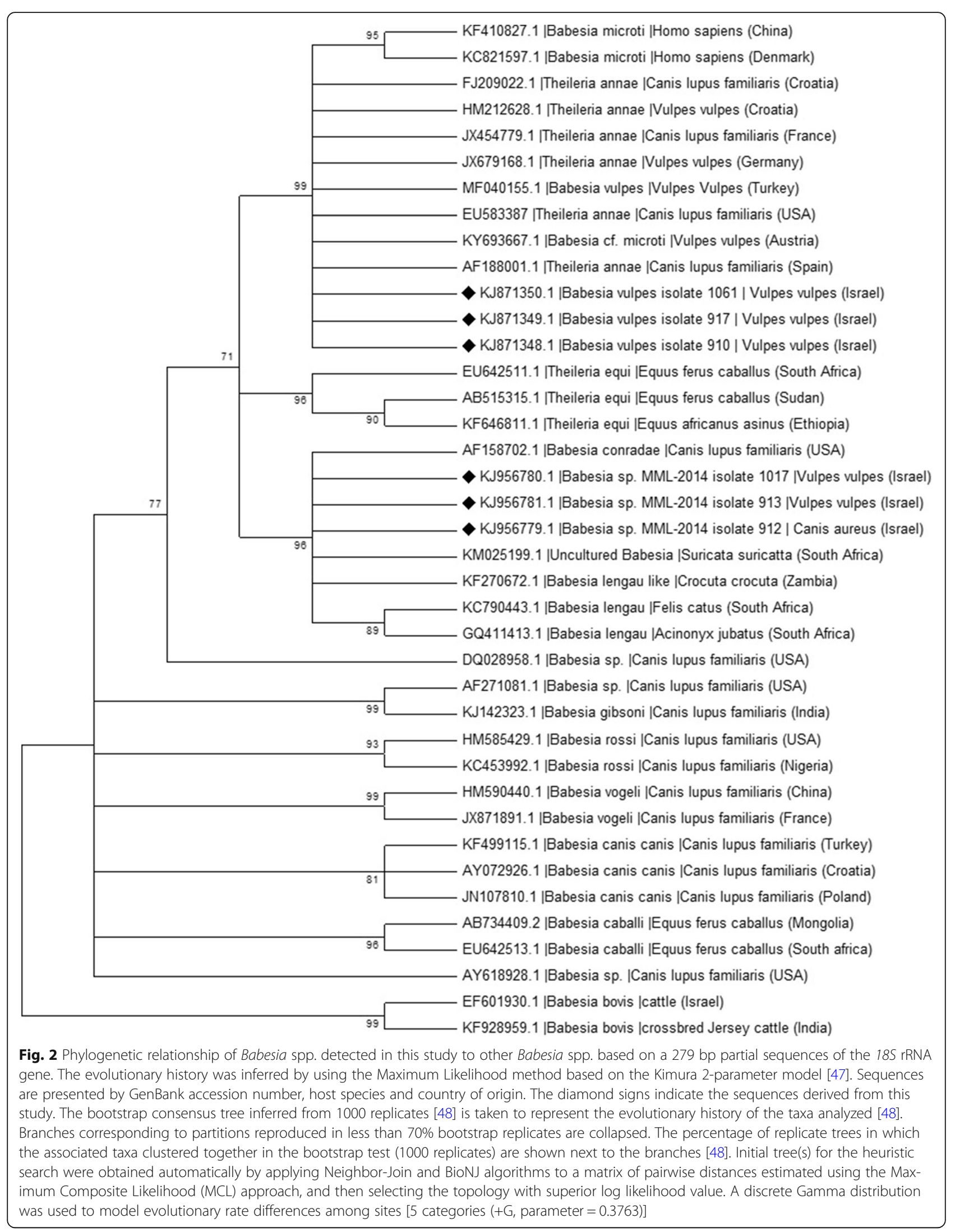


(Fig. 3) showed that when comparing longer sequences of the $18 S$ rRNA gene, "B. vulpes" from this study clustered with "T. annae" sequences from GenBank and away from B. microti and other Babesia spp. with even higher bootstrap values than in the analysis with short $18 \mathrm{~S}$ rRNA emphasizing the importance of performing the phylogenetic analysis with long DNA sequnences when available.

Sequences of the previously undescribed Babesia sp. MML from this study obtained when evaluating 312-314 bp segments of the $18 S$ rRNA amplified by the piroplasmid PCR were $97 \%$ identical to GenBank accession KF270672 of a $B$. lengau-like sequence from a hyena (Crocuta crocuta) in Zambia [13]. Two of the Babesia sp. MML sequences from red foxes were deposited in GenBank as accessions KJ956780 and KJ956781 and a sequence of this genotype from a golden jackal was deposited as KJ956779. The golden jackal sequence (KJ956779) was 98\% identical to a Babesia sp. sequence (KM025199) from a meerkat (Suricata suricatta) from South Africa [23] (Table 2). These three Babesia sp. MML sequences from the current study clustered together in a phylogenetic analysis of short $18 S$ rRNA sequences
(Fig. 2) with the B. lengau-like sequence from a hyena (C. crocuta) in Zambia and a Babesia conradae sequence from a domestic dog from California, USA. and close to a sub-clade with $B$. lengau sequences from a domestic cat and a cheetah (Acinonyx jubatus) from South Africa,

In the additional Babesia spp. phylogenetic tree based on longer Babesia 18S rRNA gene sequences of 1490 bp (Fig. 3), two long $18 S$ rRNA sequences of this new genotype from red foxes in Israel deposited in GenBank (KJ956782, KJ956783) clustered significantly separately from B. lengau sequences and from $B$. conradae and other Babesia spp.

Further characterization of the new Babesia sp. MML carried out by amplification of the Babesia rRNA gene ITS2 region yielded two sequences from red foxes deposited in GenBank (KR709304, MG461686) and a sequence from a golden jackal (MG461685) which were only 87\% identical to the $B$. lengau-like sequence from a hyena $(C$. crocuta) in Zambia (KF510019), which was the closest sequence to the $18 S$ rRNA gene sequences of the new genotype. These red fox and jackal sequences from Israel clustered in a phylogenetic tree based on 290 bp sequences of the ITS2 of Babesia

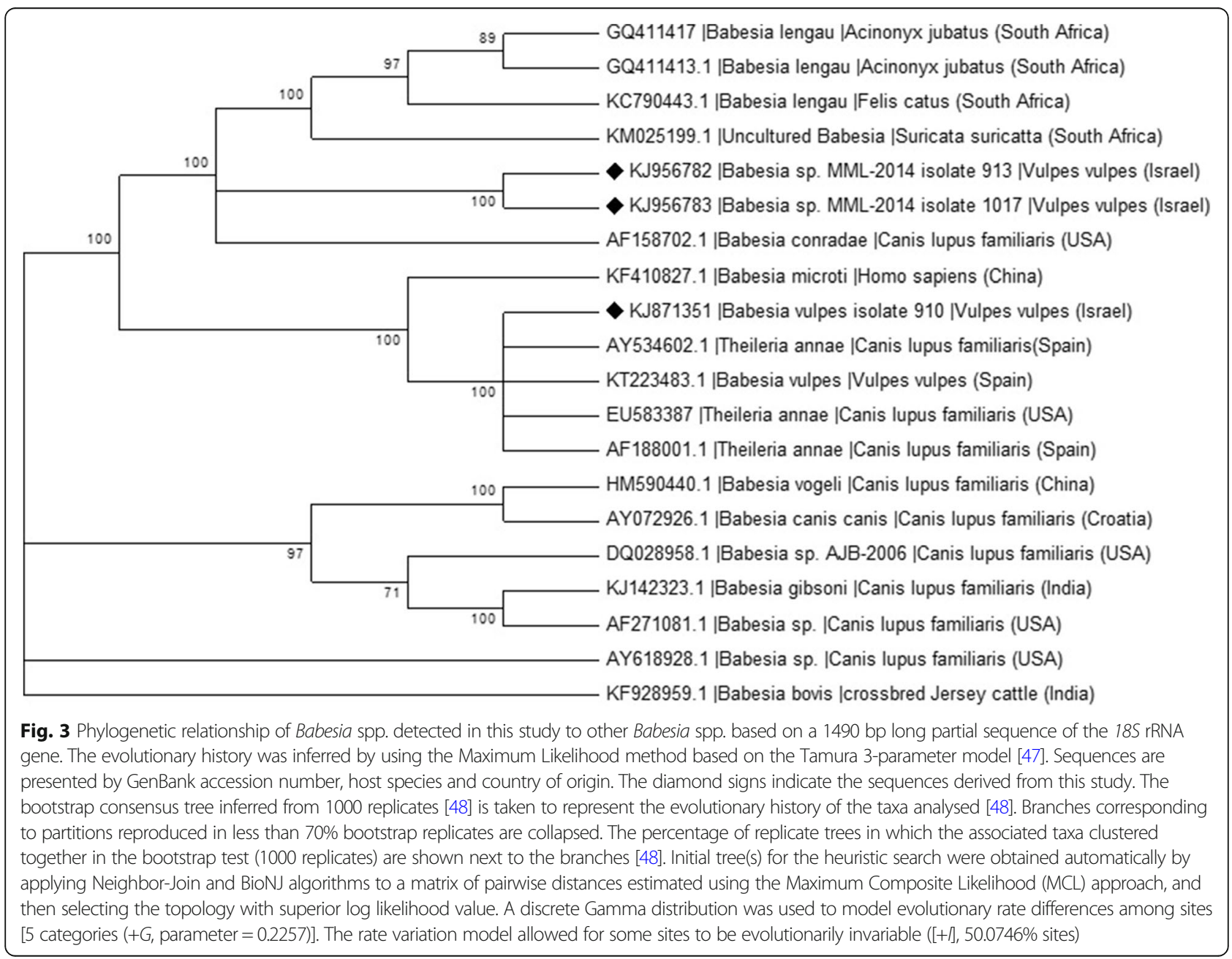


spp. significantly seperate from $B$. lengau, $B$. lengau-like, $B$. conaradae and other species (Fig. 4). These results show that despite the $97 \%$ identity with the B. lengau-like $18 S \mathrm{rRNA}$ sequence from Zambia and to $B$. lengau, the ITS2 region was considerably different from $B$. lengau and was likely to belong to a different Babesia sp.

\section{Discussion}

Infection of wild canid species with tick-borne infections are common globally and vary regionally in the identity of the infectious agents and prevalence values. Although many studies have been published on Hepatozoon and $\mathrm{Ba}$ besia spp. infection in red foxes, only a few publications have addresses these infections in golden jackals [24-27]. The high prevalence of $H$. canis in both jackals (46\%) and foxes $(43 \%)$ in Israel is in agreement with the high prevalence of this infection in domestic dogs [28] and the abundance of its vectors, Rhipicephalus sanguineus (sensu lato) and Rhipicephalus turanicus in this country [29]. Studies from European countries have also found high levels of $H$. canis infection in several countries, including in areas where $R$. sanguineus (s.l.) is not present, and therefore it was suggested that other vector ticks or different mechanisms of transmission such as transplacental transmission and carnivorism of infected hosts have a major role in the parasite's transmission in foxes [30, 31]. It is probable that $H$. canis is well adapted to infecting foxes and jackals and is seldom associated with a severe disease as its high prevalence in these wild canids populations would not be expected if it was a common cause of severe disease.
"Babesia vulpes" has also been reported to be a frequent cause of infection in red fox populations in Europe and North America and recently also in the Asian part of Turkey $[8-10,32]$. This is the first report of its presence in Israel, and there have not been any reports of its infection in domestic dogs, contrary to reports from countries such as Spain, Portugal and Croatia where infection of both dogs and red foxes have been reported [33-36]. The prevalence of "B. vulpes" infection (26\%) found in red foxes in Israel in the current study based on a small animal sample is higher than found in Hungary (20\%) [37] and lower than the 46\%,50\% and 69\% found in Austria, Germany and Portugal, respectively [9, 10, 12]. To date, infection of golden jackals with "B. vulpes" has only been reported previously once in 2/52 (4\%) jackals from Romania [27]. "Babesia vulpes" has also been described in other canid species including the racoon dog (Nyctereutes procyonoides) in Austria [38], and the gray fox (Urocyon cinereoargenteus) in North America [8]. No "B. vulpes" was detected in jackals from Israel in this study and there have also not been any reports of domestic dog infection with this Babesia sp. in Israel to date. The tick vector or vectors of "B. vulpes" have not been incriminated yet, although several species of Ixodes have been implicated as possible vectors [39]. Interestingly, Ixodes spp. are rare in Israel and not likely to be the vectors of "B. vulpes" among red foxes in this country [40].

The detection of Babesia sp. MML in both foxes and jackals in this study is interesting since this Babesia genotype has not been reported before. Babesia lengau was initially described in cheetahs in South Africa and subsequently also

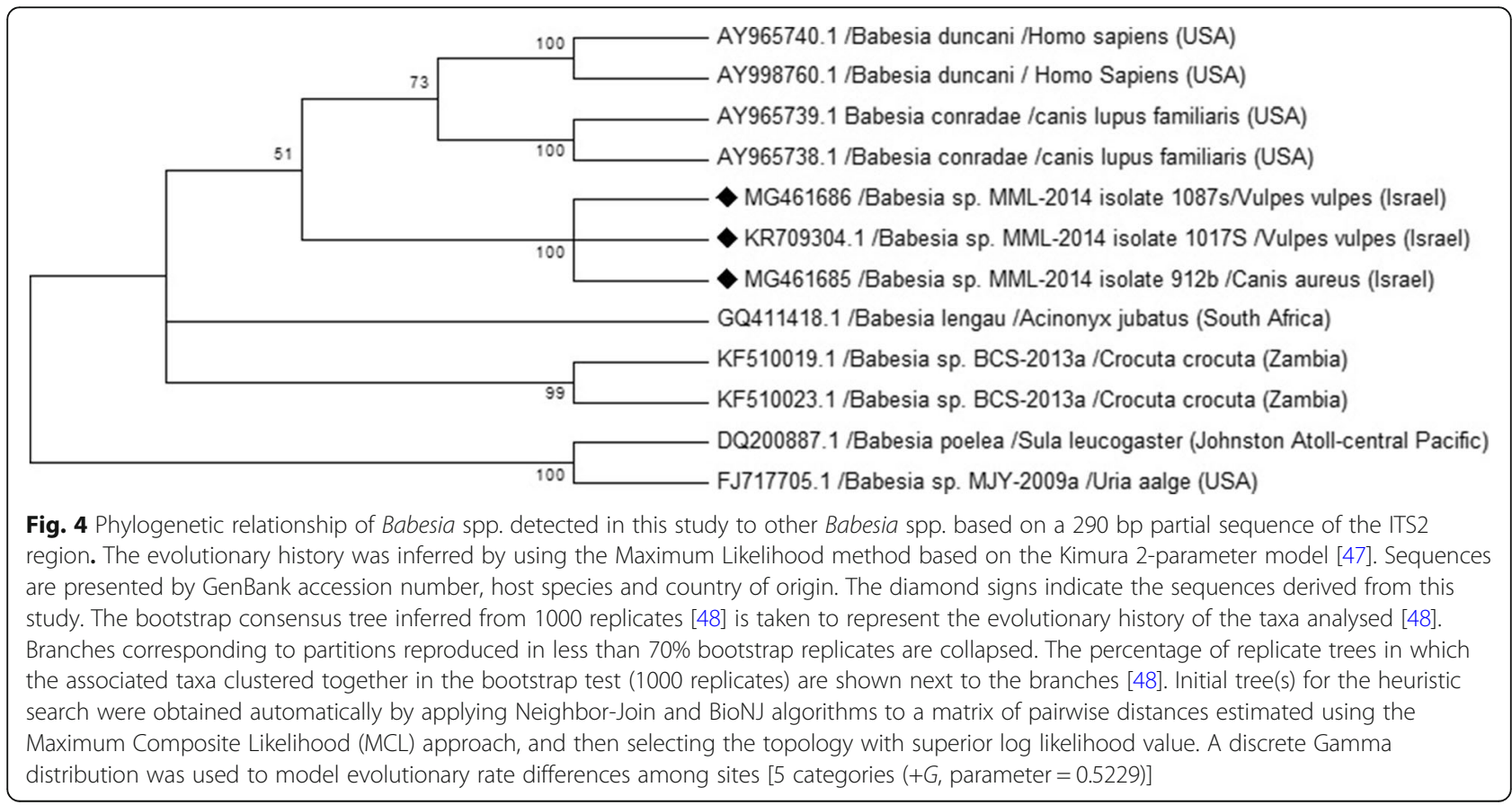


associated with severe disease in two domestic cats from this country [41, 42]. Different $B$. lengau-like genotypes were detected in spotted hyenas (C. crocuta) and a lion (Panthera leo) in Zambia [13], brown hyenas (Parahyaena brunnea) and spotted hyenas in Namibia and South Africa [43] and lions in Botswana [44]. In addition, a hemolytic disease in sheep was attributed to a $B$. lengau-like piroplasm in northern Greece [45]. There appear to be a multitude of genotypes related to $B$. lengau described mainly from carnivores in southern Africa. We have characterized the new Babesia genotype from our study further by sequencing the ITS2 region and found it significantly different to B. lengau from cheetahs [41], and have therefore decided to term this genotype from foxes and jackals Babesia sp. MML.

Hepatozoon canis and Babesia sp. MML were found both in the blood and spleen of infected animals in this study, whereas "B. vulpes" was found only in the blood of foxes and not in the spleen. Other studies have shown that "B. vulpes" can be detected in the spleen [11]; however, two studies on foxes from Austria found that blood was more suitable for its detection that the spleen $[10,11]$, and blood is also preferred for "B. vulpes" detection in the fox over bone marrow [9]. While the current study found a higher prevalence of $H$. canis infection in the blood of jackals compared to their spleen, the spleen of foxes was a better tissue for the detection than blood in this study, in agreement with a study from western Austria [11].

The lack of significant difference in the presence of infection with the three parasites in jackals or foxes of different ages and gender is in agreement with findings from a study on vector-borne pathogens of foxes in Austria where H. canis and "B. vulpes" were studied [11]. Similar results on lack of influence of age and gender were also found for "B. vulpes" infection in foxes from Portugal [9]. When comparing to domestic dog infection with $H$. canis, in a survey of 694 dogs from Turkey, no difference in gender was found for dogs infected with $H$. canis; however, adult dogs were more frequently infected than young dogs [46]. In a study on Spanish dogs with clinical disease due to "B. vulpes", no differences were noted in dog gender; however, dogs younger than 3 years of age were more susceptible to disease in comparison to older dogs [36]. These findings suggest that dogs and red foxes of both genders are probably equally susceptible to $H$. canis or to "B. vulpes" infection. The differences between foxes and dogs are related to age susceptibility with adult dogs more frequently infected with $H$. canis than young dogs whereas foxes of all ages were equally infected, and with young dogs showing more clinical disease with "B. vulpes" than old dogs. In contrast, the lack of age differences in fox infection may stem from differences in transmission pathways or degree of environmental exposure to the parasites and their vectors. The lack of significant differences in the prevalence of infection of the three parasites detected among jackals and foxes in North, Central and South Israel may be due to the small sample size, or to the fact that Israel is small (424 km from South to North and $114 \mathrm{~km}$ at its widest point). Distances between areas are short and without substantial boundaries which are difficult to cross, and therefore movement of wild canids from one area to another is likely.

This study had several limitations. It included a small number of red foxes and therefore might have missed some findings that could have been discerned from evaluating larger numbers of foxes and golden jackals. Furthermore, some information on age, gender and geographic location was missing for some of the animals. In addition, no co-infection was detected as the initial screening assay used and its sequencing directed to either Hepatozoon or Babesia infection, and led to additional PCRs as needed for characterization of the parasites identified initially.

This report represents the most southern point in which "B. vulpes" has been reported to date. The presence of "B. vulpes" in the fox population, which is known to be severely virulent to domestic dogs $[33,36]$, is a potential threat to the health of the canine population of Israel and the Middle East. Widespread $H$. canis infection of wild canids in Israel may present an important reservoir for infection of domestic dogs, as ticks feeding on jackals and foxes may infect dogs living in the same area because these wild canids often reach human dwellings in search of food and water. Furthermore, the newly detected Babesia sp. MML may prove to be pathogenic to wild canids as well as to domestic animals, and therefore requires further research and characterization.

\section{Conclusions}

In conclusion, $H$. canis was found to infect close to half of the jackals and foxes included in the study, representing a high infection value with this pathogen in Israel. "Babesia vulpes" is reported for the first time in Israel and its infection may spread further to other canid species, and a new Babesia genotype was detected in both foxes and jackals and should be studied further to understand its possible pathogenicity and virulence to its hosts and other animals.

\section{Abbreviations}

Cl: 95\% confidence interval; PCR: Polymerase chain reaction; rRNA: Ribosomal RNA

\section{Acknowledgements}

Publication of this paper has been sponsored by Bayer Animal Health in the framework of the 13th CVBD World Forum Symposium. The authors thank Dr Gila Sutton for her help in analyzing the data.

\section{Funding}

Not applicable.

\section{Availability of data and materials}

All data generated or analyzed during this study are included in this published article. Representative sequences were submitted to the GenBank

database under the accession numbers KJ868814-KJ868819 (H. canis); KJ871348-KJ871351 ("Babesia vulpes"); KJ956779-KJ956783; KR709304; MG461685; MG461686 (Babesia sp. MML). 


\section{Authors' contributions}

MML performed PCR and sequencing and participated in writing the manuscript. YNB performed the PCR, analyzed the DNA sequences and phylogenetic analysis. RK collected the animal samples and participated in conceiving the manuscript. GB planned the study, analyzed the data and wrote the manuscript. All authors read and approved the final manuscript.

\section{Ethics approval and consent to participate}

Samples were collected from wild golden jackals and red foxes by wardens of the Israel Nature and Parks Authority as a part of a national study on the prevalence of leishmaniosis in wildlife animals. Trapping and sampling of animals was performed by wardens of the Israel Nature and Park Authorities with an approved permit from this agency and the study was conducted adhering to the Hebrew University's guidelines for animal husbandry and use of animals in research.

\section{Consent for publication}

Not applicable.

\section{Competing interests}

The authors declare that they have no competing interests.

\section{Publisher's Note}

Springer Nature remains neutral with regard to jurisdictional claims in published maps and institutional affiliations.

\section{Author details}

${ }^{1}$ Koret School of Veterinary Medicine, The Hebrew University of Jerusalem, Rehovot, Israel. ${ }^{2}$ Israel Nature and Parks Authority, Jerusalem, Israel.

\section{Received: 15 November 2017 Accepted: 15 February 2018} Published online: 20 March 2018

\section{References}

1. Smith TG. The genus Hepatozoon (Apicomplexa: Adeleina). J Parasitol. 1996; 82:565-85.

2. Baneth G. Perspectives on canine and feline hepatozoonosis. Vet Parasitol. 2001;181:3-11

3. Solano-Gallego L, Baneth G. Babesiosis in dogs and cats - expanding parasitological and clinical spectra. Vet Parasitol. 2011;181:8-60.

4. Alvarado-Rybak M, Solano-Gallego L, Millán J. A review of piroplasmid infections in wild carnivores worldwide: importance for domestic animal health and wildlife conservation. Parasit Vectors. 2016:9:538.

5. Irwin PJ. Canine Babesiosis. Vet Clin North Am Small Anim Pract. 2010;40(6): 1141-56.

6. Vincent-Johnson NA. American canine hepatozoonosis. Vet Clin North Am Small Anim Pract. 2003:33:905-20.

7. Penzhorn BL. Why is southern African canine babesiosis so virulent? An evolutionary perspective. Parasit Vectors. 2011:4:51.

8. Birkenheuer A, Horney B, Bailey M, Scott M, Sherbert B, Catto V, et al. Babesia microti-like are prevalent in north American foxes. Vet Parasitol. 2010;172:179-82.

9. Cardoso L, Cortes HC, Reis A, Rodrigues P, Simões M, Lopes A, et al. Prevalence of Babesia microti-like infection in red foxes (Vulpes vulpes) from Portugal. Vet Parasitol. 2013;196:90-5.

10. Duscher G, Fuehrer HP, Kübber-Heiss A. Fox on the run - molecular surveillance of fox blood and tissue for the occurrence of tick-borne pathogens in Austria. Parasit Vectors. 2014;7:521.

11. Hodžić A, Mrowietz N, Cézanne R, Bruckschwaiger P, Punz S, Habler VE, et al. Occurrence and diversity of arthropod-transmitted pathogens in red foxes (Vulpes vulpes) in western Austria, and possible vertical (transplacental) transmission of Hepatozoon canis. Parasitology. 2017;24:1-10.

12. Najm NA, Meyer-Kayser E, Hoffmann L, Herb I, Fensterer V, Pfister K, et al. A molecular survey of Babesia spp. and Theileria spp. in red foxes (Vulpes vulpes) and their ticks from Thuringia, Germany. Ticks Tick Borne Dis. 2014;5: 386-91

13. Williams BM, Berentsen A, Shock BC, Teixiera M, Dunbar MR, Becker MS, et al. Prevalence and diversity of Babesia, Hepatozoon, Ehrlichia, and Bartonella in wild and domestic carnivores from Zambia, Africa. Parasito Res. 2014;113:911-8.
14. Fishman Z, Gonen L, Harrus S, Strauss-Ayali D, King R, Baneth G. A serosurvey of Hepatozoon canis and Ehrlichia canis antibodies in wild red foxes (Vulpes vulpes) from Israel. Vet Parasitol. 2004;119:21-6.

15. Ebani W, Rocchigiani G, Nardoni S, Bertelloni F, Vasta V, Papini RA, et al. Molecular detection of tick-borne pathogens in wild red foxes (Vulpes vulpes) from central Italy. Acta Trop. 2017:172:197-200.

16. Movilla R, Altet $L$, Serrano L, Tabar MD, Roura X. Molecular detection of vector-borne pathogens in blood and splenic samples from dogs with splenic disease. Parasit Vectors. 2017;10:131.

17. Tabar MD, Altet L, Francino O, Sánchez A, Ferrer L, Roura X. Vector-borne infections in cats: molecular study in Barcelona area (Spain). Vet Parasitol. 2008;151:332-6.

18. Baneth G, Sheiner A, Eyal O, Hahn S, Beaufils JP, Anug Y, et al. Redescription of Hepatozoon felis (Apicomplexa: Hepatozoidae) based on phylogenetic analysis, tissue and blood form morphology, and possible transplacental transmission. Parasit Vectors. 2013;6:102

19. Birkenheuer AJ, Levy MG, Breitschwerdt EB. Development and evaluation of a seminested PCR for detection and differentiation of Babesia gibsoni (Asian genotype) and B. canis DNA in canine blood samples. J Clin Microbiol. 2003; 41:4172-7.

20. Shock BC, Birkenheuer AJ, Patton LL, Olfenbuttel C, Beringer J, Grove DM, et al. Variation in the ITS-1 and ITS-2 rRNA genomic regions of Cytauxzoon felis from bobcats and pumas in the eastern United States and comparison with sequences from domestic cats. Vet Parasitol. 2012;190:29-35.

21. Tamura T, Stecher G, Peterson D, Filipski A, Kumar S. MEGA6: Molecular Evolutionary Genetics Analysis version 6.0. Mol Biol Evol. 2013;30:2725-9.

22. Landis JR, Koch GG. The measurement of observer agreement for categorical data. Biometrics. 1977:33:159-74.

23. Leclaire S, Menard S, Berry A. Molecular characterization of Babesia and Cytauxzoon species in wild South African meerkats. Parasitology. 2015: 142:543-8.

24. Duscher GG, Kübber-Heiss A, Richter B, Suchentrunk F. A golden jacka (Canis aureus) from Austria bearing Hepatozoon canis-import due to immigration into a non-endemic area? Ticks Tick Borne Dis. 2013:4:133-7.

25. Farkas R, Solymosi N, Takács N, Hornyák Á, Hornok S, Nachum-Biala Y, et al. First molecular evidence of Hepatozoon canis infection in red foxes and golden jackals from Hungary. Parasit Vectors. 2014;7:303.

26. Maia JP, Alvares F, Boratyński Z, Brito JC, Leite JV, Harris DJ. Molecular assessment of Hepatozoon (Apicomplexa: Adeleorina) infections in wild canids and rodents from North Africa, with implications for transmission dynamics across taxonomic groups. J Wildl Dis. 2014;50:837-48.

27. Mitková B, Hrazdilová K, D'Amico G, Duscher GG, Suchentrunk F, Forejtek P, et al. Eurasian golden jackal as host of canine vector-borne protists. Parasit Vectors. 2017;10:183

28. Baneth G, Shkap V, Presentey BZ, Pipano E. Hepatozoon canis: the prevalence of antibodies and gametocytes in dogs in Israel. Vet Res Commun. 1996:20:41-6.

29. Mumcuoglu KY, loffe-Uspensky I, Alkrinawi S, Sarov B, Manor E, Galun R. Prevalence of vectors of the spotted fever group rickettsiae and murine typhus in a Bedouin town in Israel. J Med Entomol. 2001;38:458-61.

30. Tolnai Z, Sréter-Lancz Z, Sréter T. Spatial distribution of Anaplasma phagocytophilum and Hepatozoon canis in red foxes (Vulpes vulpes) in Hungary. Ticks Tick Borne Dis. 2015:6:645-8.

31. Mitková B, Hrazdilová K, Steinbauer V, D'Amico G, Mihalca AD, Modrý D. Autochthonous Hepatozoon infection in hunting dogs and foxes from the Czech Republic. Parasitol Res. 2016;115:4167-71.

32. Orkun Ö, Karaer Z. Molecular characterization of Babesia species in wild animals and their ticks in Turkey. Infect Genet Evol. 2017;55:8-13.

33. García AT. Piroplasma infection in dogs in northern Spain. Vet Parasitol. 2006:138:97-102.

34. Beck R, Vojta L, Mrljak V, Marinculić A, Beck A, Zivicnjak T. Diversity of Babesia and Theileria species in symptomatic and asymptomatic dogs in Croatia. Int J Parasitol. 2009;39:843-8.

35. Simões PB, Cardoso L, Araújo M, Yisaschar-Mekuzas $Y$, Baneth G. Babesiosis due to the canine Babesia microti-like small piroplasm in dogs - first report from Portugal and possible vertical transmission. Parasit Vectors. 2011;4:50

36. Miró G, Checa R, Paparini A, Ortega N, González-Fraga JL, Gofton A, et al. Theileria annae (syn. Babesia microti-like) infection in dogs in NW Spain detected using direct and indirect diagnostic techniques: clinical report of 75 cases. Parasit Vectors. 2015;8:217. 
37. Farkas R, Takács N, Hornyák Á, Nachum-Biala Y, Hornok S, Baneth G. First report on Babesia cf. microti infection of red foxes (Vulpes vulpes) from Hungary. Parasit Vectors. 2015;8:55.

38. Duscher T, Hodžić A, Glawischnig W, Duscher GG. The raccoon dog (Nyctereutes procyonoides) and the raccoon (Procyon lotor)-their role and impact of maintaining and transmitting zoonotic diseases in Austria, central Europe. Parasitol Res. 2017;116:1411-6.

39. Baneth G, Florin-Christensen M, Cardoso L, Schnittger L. Reclassification of Theileria annae as Babesia vulpes sp. nov. Parasit Vectors. 2015;8:207.

40. Erster O, Roth A, Hadani Y, Shkap V. First detection of Ixodes ricinus on beef cattle in Israel. Vet Parasitol. 2013;191:394-9.

41. Bosman AM, Oosthuizen MC, Peirce MA, Venter EH, Penzhorn BL. Babesia lengau sp. nov., a novel Babesia species in cheetah (Acinonyx jubatus, Schreber, 1775) populations in South Africa. J Clin Microbiol. 2010;48(8):2703.

42. Bosman AM, Oosthuizen MC, Venter EH, Steyl JC, Gous TA, Penzhorn BL. Babesia lengau associated with cerebral and haemolytic babesiosis in two domestic cats. Parasit Vectors. 2013;6:128.

43. Burroughs REJ, Penzhorn BL, Wiesel I, Barker N, Vorster I, Oosthuizen MC. Piroplasms in brown hyaenas (Parahyaena brunnea) and spotted hyaenas (Crocuta crocuta) in Namibia and South Africa are closely related to Babesia lengau. Parasitol Res. 2017;116:685-92.

44. McDermid KR, Snyman A, Verreynne FJ, Carroll JP, Penzhorn BL, Yabsley MJ. Surveillance for viral and parasitic pathogens in a vulnerable African lion (Panthera leo) population in the northern Tuli Game Reserve, Botswana. J Wildl Dis. 2017;53:54-61.

45. Giadinis ND, Chochlakis D, Kritsepi-Konstantinou M, Makridaki E, Tselentis Y, Kostopoulou D, et al. Haemolytic disease in sheep attributed to a Babesia lengau-like organism. Vet Rec. 2012;170:155.

46. Aktas M, Özübek S, Altay K, Balkaya I, Utuk AE, Kırbas A, et al. A molecular and parasitological survey of Hepatozoon canis in domestic dogs in Turkey. Vet Parasitol. 2015;209:264-7.

47. Hasegawa M, Kishino H, Yano T. Dating of the human-ape splitting by a molecular clock of mitochondrial DNA. J Mol Evol. 1985:22:160-74.

48. Felsenstein J. Confidence limits on phylogenies: an approach using the bootstrap. Evolution. 1985:39:783-91.

\section{Submit your next manuscript to BioMed Central and we will help you at every step:}

- We accept pre-submission inquiries

- Our selector tool helps you to find the most relevant journal

- We provide round the clock customer support

- Convenient online submission

- Thorough peer review

- Inclusion in PubMed and all major indexing services

- Maximum visibility for your research

Submit your manuscript at www.biomedcentral.com/submit
Biomed Central 